\title{
Interplay Between the Human Resource Development Activities and Organizational
} Commitment

\author{
Kristinka Ovesni \\ Nataša Matović \\ Ivana Luković
}

Department for Pedagogy and Andragogy, Faculty of Philosophy, University of Belgrade

\begin{abstract}
This mixed methods research was aimed to explore relationship between the human resource development activities and the commitment of employees. In the research, we applied explanatory sequential design using nested samples for the quantitative and qualitative components of the study to foster deeper understandings of these relationships. In the quantitative component, data were obtained with scales, and analyzed from 609 employees in different companies in Serbia, while for qualitative component semi-structured interviews were conducted with 29 respondents from the same sample. The collected data were subjected (in the first component) to a few common (frequencies, std. deviation, means, etc.) and more complex statistical proceedings (canonical correlation analysis), and in the second component were subjected to the qualitative content analysis. The quantitative results indicate complex interaction of affective, continuance, and normative components of organizational commitment with different human resource development activities, while the qualitative data revealed deeper meaning of these connections. ${ }^{1}$
\end{abstract}

Keywords: human resource development, human resource development activities, organizational commitment, mixed methods

\section{Introduction}

The reason to research the interconnection of human resource development activities and organizational commitment, we found in fact that it is a relatively a new paradigm in HRD studies. Most of papers related to this issue are written from the perspective of learning organization concept, from perspective of new employees, older workers, certain professions or the fields of practice, or considering only limited spectrum of HRD activities - training, virtual HRD activities, etc. Nearly all of studies treated relationships between HRD activities and organizational commitment as one of the research questions. Only a few quantitative studies aimed to investigate relationships between HRD activities and organizational commitment were performed recently (Bartlett, 2001; Tansky and Cohen, 2001, In Chalofsky, et al., 2014), while qualitative and mixed method studies were missing. Based on lack of empirical studies of the interconnection of HRD activities and organizational commitment, we decided to research it using an explanatory sequential design.

\section{Human Resource Development Activities}

Human resource development (HRD) activities are designed to contribute to the achievement of strategic objectives of the organization, to produce changes in behavior of individuals, group or organization, to help organization to obtain higher performance, and aimed to enrich and develop employee's work-related potential through learning and training. They encompass "a whole network of activities involved in preparing people for work and coping with a multitude of issues related to work" (Ruona, 2000: 14).

\footnotetext{
1 This article is a result of the project "Models of evaluation and strategies for improvement of education quality in Serbia", No 179060 (2011-2015), financially supported by the Ministry of Education, Science and Technological Development, Republic of Serbia.
} 
According to Hamlin and Stewart, HRD activities are a workplace process that encompasses "planned activities, processes and/or interventions designed to have impact upon and enhance organizational and individual learning, to develop human potential, to improve or maximize effectiveness and performance at either the individual, group/team and/or organizational level, and/or to bring about effective, beneficial personal or organizational behavior change" (Hamlin and Stewart, 2011: 213). Moreover, these activities include not only "cognitive activity but also involve the emotional, imaginative, and intuitive aspects of humanity" (Bennett and Bierema, 2010: 641).

Although earlier studies emphasized that through HRD activities learning is related to attaining organizational and not necessarily individual performance goals, many latter authors (Reio, 2013; Sambrook, 2002; Slattery et al., 2006; Wilton, 2013) consider that HRD activities, whether face to face or virtual, encompass not only adult education/learning activities (long- and short-term, self-development, collaborative, organization- or socially-oriented), but also, broader spectrum of activities aimed to improve organizational culture, organizational climate, through processes of: appraising and rewarding, leading, directing, motivating, building trust, taking risks, developing new knowledge, sharing knowledge, etc. Garavan and associates consider that "HRD activities may be multidimensional, including combinations of voluntary, involuntary, formal and informal, current and future, incremental as well as frame breaking, interactive and passive learning activities, and generic and specific competencies" (Garavan et al., 2004: 427).

Very interesting classification of HRD activities related to learning is given by Rowden (2002: 410-417): (a) formal (structured, planned, organized) learning activities, (b) informal (unstructured, or spontaneous) activities that lead to learning on the job, (c) incidental (activities that lead to learning on the job, even though that was not the purpose of it, which occurs as an unintended by-product of some other activity, such as trial-and-error experimentation or interpersonal interaction), and (d) overall learning activities that combines the three aspects of workplace learning. He extended understanding that most of the HRD activities related to learning are intentional, i.e. formal or informal. Rowden (2002: 410) emphasizes that HRD activities are a means of achieving various organizational and individual goals.

Besides traditional practices of formal and informal learning activities, described by Rowden (2002) we found several interesting characteristics of the contemporary HRD activities. Knowles et al. (1998: 121) wrote about "self-initiated activities" performed by employees who "are not asked to do it", when facing new challenges on the job that benefits organizations. Supported by development of new technologies, needs for sharing knowledge in organization, global- and market-driven economy, "just-in-time" (JIT) learning activities at workplace emerged as unstructured, but important HRD practice. As Tkaczyk (2017) recently emphasized, earlier orientation in HRD activities were "just-in-case" oriented, trainercentered, centralized, ad hoc, bureaucratic, mechanistic, menu-driven, reactive, and short-term. As opposition to them, "the new learning and development function is being identified by employees and company leaders [...] as learner-centered, agile, energized, holistic, humanistic, just-in-time, on-demand, commitment-focused, knowledge-led, organic, integrated, strategic, networked, and long-term" (Tkaczyk, 2017: 11). These "new" activities are practice-oriented, intended to be applied at the job. Moreover, there are many other HRD activities that do not belong to these groups because they do not belong to traditional adult education or human resource development paradigms (i.e. learning oriented evaluative activities, organizational learning activities, solving-problems activities, etc.), or because they are not aimed only to work-relatedlearning (i.e. supportive, provisional, motivational, festive activities, etc.).

\section{Organizational Commitment}

Organizational commitment is a construct that been defined in relevant literature in many various ways. Some authors (Bishop \& Scott, 2000, Vandenberg, \& Scarpello, 1994, In Meyer, 2014; Joo, 2010) treated commitment as a unidimensional construct, while others (Johnson, 1991, In Reis and Sprecher, 2009; Meyer et al., 2010, In Meyer, 2014; Rusbult, 1983, In Reis and Sprecher, 200;) were applied a multidimensional framework. Joo consider that organizational commitment "refers to an individual's overall feelings about the organization", and that this construct is related to "behavioral investments in the organization, likelihood to stay with the organization, and goal and value congruence" (Joo, 2010: 70). Rusbult defined commitment as "the subjective experience of dependence and is a function of three independent variables: satisfaction level, quality of alternatives, and investment size" (Rusbult, 1983, In Reis and Sprecher, 2009: 246). Meyer \& Herscovitch described commitment as "stabilizing or obliging force that gives direction to behavior", i.e. "mind-set that can take different forms and binds an individual to a course of action that is relevant to a particular target" (Meyer \& Herscovitch, 2001: 301, In Meyer, 2014: 35-36). 
Meyer et al. (Meyer et al., 2010, In Meyer, 2014) consider that commitment is construct formed by three basic components - affective, continuance and normative. Intensity of commitment is moving along the continuum of engagement, and depends from work motivation. The affective commitment (attachment) can be described as emotional bond with an entity (organization) that involve acceptance of value system and identification with an entity. The continuance commitment (gratitude) can be described as a perceived cost of leaving organization, or as a perceived lack of position and benefits in the case of leaving organization. The normative commitment (loyalty) can be described as a perception of obligation to remain in organization due to ethical reasons.

Earlier definitions been grounded in understanding that organizational commitment is force that drive an individual to an entity. However, contemporary definitions underline that organizational commitment is attachment, that connects an individual to an entity and/or to behavior (Miroshnik, 2013). Although subtle, that difference emphasizing importance of extrinsic motivation and external requests (through formal or informal organizational regulative, processed through management requirements or through organizational culture) given in former definition, that notably reflect on continuance commitment.

\section{Human Resource Development Activities and Organizational Commitment Relations}

To date, not too much is known about the relationship between HRD activities and organizational commitment. Some earlier studies (Ashforth \& Mael, 1989, In Slattery et al., 2006) revealed that HRD practices influence organizational commitment through the development of an employee's organizational socialization. An earlier study, conducted by Mathieu (1991) provides a base for examining the relationship between training activities as one of the aspect of HRD activities with organizational commitment. Based on responses from 588 ROTC (Army and Navy Reserve Officer Training Corps) cadets he found, opposite to earlier studies, that "the influences of training characteristics on organizational commitment were completely mediated by their impact on satisfaction" (Mathieu, 1991: 616).

Recently, few studies have investigated this relationship as one of the research questions. Slattery et al. (2006) in their empirical study found importance of HRD activities during new employee development practices for development of three aspects of commitment - loyalty, attachment and involvement. Bartlett found that "organizational commitment is an additional outcome of training and development activities", i.e. that "that training can play a role in the development and maintenance of organizational commitment" (Bartlett, 2001: 348). Similarly, Hartung and Wilson (2016) highlighted that HRD activities may support participants' building commitment, while Tansky and Cohen reported in their study that satisfaction with employee development resulted in more commitment to the organization (Tansky and Cohen, 2001, In Chalofsky, et al., 2014). Some authors (Ruona, 2014, Nafukho and Muyia, 2014, all In Chalofsky, et al., 2014; Thurston et al., 2012) found that HRD activities could foster and stimulate organizational commitment, i.e. to activate and build organizational commitment (Swanson and Holton, 2001).

\section{Research Questions}

This study was aimed to explore relationship between the human resource development activities and the commitment of employees. Relationship between different aspects of HRD activities (frequency of participation, content of activities, applicability of knowledge and skills obtained through HRD activities to practice, motivation for organizational and jobrelated learning, support to employees' learning, learning through evaluation, and availability of job-relevant information) and major components of commitment - affective, continuance and normative were explored through the following research questions:

1. How frequency of participation in HRD activities relate to organizational commitment of employees?

2. How content of HRD activities relate to organizational commitment of employees?

3. How applicability of knowledge and skills obtained through HRD activities to practice relate to organizational commitment of employees?

4. How motivation for organizational and job-related learning relates to organizational commitment of employees?

5. How support to employees' learning relates to organizational commitment of employees? 
6. How learning through evaluation relates to organizational commitment of employees?

7. How availability of job-relevant information relates to organizational commitment of employees?

\section{Methods}

This mixed methods research was aimed to explore relationship between the human resource development activities and the commitment of employees. The rationale to opt for this design, according to one of the most accepted classifications of the purposes for mixed-method evaluation designs given by Greene and associates is complementarity (Greene, et al., 1989). In that research design purpose of combination of quantitative and qualitative methods are to obtain more in-depth insights into the nature of relationship through qualitative methods; in the case of this study, our intention was to increase understanding, meaningfulness, and interpretability of the results obtain by quantitative methods. The study, reported herein, involves an explanatory sequential design. In accordance to its characteristics (Creswell \& Plano Clark, 2011), we first employed quantitative, followed by qualitative component, where quantitative component has priority in the study.

\section{Sample}

The population for this study were employees from different companies in Serbia. Participation in the study was voluntary and anonymously. We opted for sequential design using nested samples for the quantitative and qualitative components of the study (Onwuegbuzie \& Collins, 2007; Matović, 2013).

By using random sampling, data for quantitative analyses were collected from employees in different organizations from 10 cities in Serbia ( $\mathrm{N}=609$ ). The on-line questionnaires were distributed to 612 respondents. We received total of 609 completed and usable surveys for a response rate of $96.8 \%$. The demographic variables included age, gender, employees' overall tenure, tenure with current employer, level of education, number of employees in organization, and industry type.

The age of the participants ranged from 18 to 67 years, with a mean age near 39 years and 3 months. Female participants $(n=377 ; 61.9 \%)$ outnumbered male participants $(n=232 ; 38.1 \%)$. Average overall tenure ranged from 6 months to over 45 years, with a mean near 13 years and 3 months, while mean of tenure with current employer were near 8 years and 8 months. Among the respondents, most of them, i.e. $28.4 \%$ had a four-year university degree, $19.4 \%$ finished vocational/craft schools, while master degree or higher had $17.9 \%$. Bachelor or college degree had $15.1 \%$ respondents, $10.0 \%$ finished gymnasiums or professional schools, professional master degree hold $7.7 \%, 1.3 \%$ hold a doctorate/PhD, while $0.3 \%$ finished only primary school. Most of the respondents (48.3\%) were engaged on various consulting positions, $19.9 \%$ were engaged as technicians, $16.9 \%$ as manual laborers, $10.2 \%$ were engaged on managerial positions, while $4.8 \%$ were engaged as researchers, university professors or university associates. Among them, $67.7 \%$ are full-time employees, $22.5 \%$ have fixed-term contracts, $5.7 \%$ are freelancers, $3.8 \%$ are volunteers, while $0.3 \%$ are re-employed pensioners.

Most of companies in which respondents are employed have less than 500 employees (70.9\%), 15.6\% have 1001-5000 employees, $8.5 \%$ have $501-1000$ employees, $3.0 \%$ have more than 10000 employees and $2.0 \%$ have $5001-10000$ employees. $73.9 \%$ organizations that employed respondents are wholesale and distribution companies, $17.6 \%$ companies are in production and the distribution of goods and services, while $8.5 \%$ of them are production companies, $22.5 \%$ respondents are employed in the education and science, $12.7 \%$ in retail, $10.9 \%$ in public services, $9.7 \%$ in communication and telecommunication, $8.6 \%$ are employed in health care, $5.5 \%$ in banking, $4.4 \%$ in lodging/food/tourism, 3.9 in automotive industry, $3.8 \%$ in art and culture, $3.3 \%$ in transportation, $3.1 \%$ in energy \& natural resources, $2.8 \%$ in construction services, while $8.9 \%$ are employed in other industries and services.

For the qualitative component, the present study employed stratified purposeful sampling. We choose that sampling by reason that some authors suggest "purposive sampling of particular cases combined with random sampling for survey to maximize both discovery and generalizability" (Greene, et al., 1989: 268). To identify respondents for the qualitative part of the study we opted for the purposeful sampling based on respondent's tenure. From the sample for quantitative component for the qualitative component of the study we selected 29 respondents, each of them with different length of tenure. Correspondingly, the sample for qualitative component of the study included similar number of randomly selected respondents with: less than five years of tenure (10 interviewees), from six to thirty years of tenure (11 interviewees), more than thirty years of tenure (8 interviewees). The average length of tenure for respondents were 15 years and 8 months. The sample included 16 female and 13 male respondents. The average age of the participants were 48 years and 2 months. 
The average tenure of interviewees was 15 years and 11 months, while the average tenure with current employer were 10 years and 4 months. Among the interviewees, most of them (51.7\%) had a four-year university degree, $24.1 \%$ had bachelor or college degree, $13.8 \%$ finished vocational/craft schools, $6.9 \%$ finished gymnasiums or professional schools, while master degree had $3.5 \%$. Most of the respondents (55.2\%) were engaged on various consulting positions, $24.1 \%$ were engaged as technicians, $13.8 \%$ were engaged on middle-range administrative positions, while $6.9 \%$ were engaged on managerial positions. Most interviewees (20.7\%) are employed in communication and telecommunication, in the field of education (13.8\%), in lodging/food/tourism (13.8\%), $10.3 \%$ of them are employed in retail, $10.3 \%$ in transportation, $6.9 \%$ in public services, $3.4 \%$ are employed in health care, $3.4 \%$ in energy \& natural resources, $3.4 \%$ in art and culture, while $13.8 \%$ are employed in other industries and services.

\section{Instruments}

To conduct the quantitative empirical research few instruments were prepared and adapted. Instruments development involved several stages. First, we developed a pool of items for each construct using a deductive approach, based on lists of common HRD activities derived in prior studies (Knowles, et al., 1998; Marsick, et al., In Chalofsky, et al., 2014; Ovesni, 2014; Rigg, et al., 2007; Swanson and Holton, 2001; Watkins \& Marsick, 1993). This first stage's content validity was assessed using survey research through independent crosschecking by seven andragogy/HRD experts. Based on their suggestions the list of questions was shortened, and the correction of text translated from English to Serbian were performed to assure the accuracy of the items. Table 1 shows internal reliability coefficient, Cronbach's a for all instruments used for collecting data for quantitative component of the study.

To measure different aspects of HRD activities (frequency of participation, content of activities, applicability of knowledge and skills obtained through HRD activities to practice, motivation for organizational and job-related learning, support to employees' learning, learning through evaluation, and availability of job-relevant information), we used 8 instruments. Frequency of participation in organized HRD activities (FP scale) was measured by 18-items instrument. A three-point frequency rating scale with anchors ranging from 1 ("never"), 2 ("rarely"), to 3 ("often") was used. For CA, AKS, ML, SL, LE, and Al scales each item had the response options to three choices, i.e. "1 = almost always", "2 = to a considerable degree" or "3 = seldom".

To measure organizational commitment, in 41-items instrument (OC scale) we used a three-point rating scale with anchors ranging from 1 ("agree"), 2 ("undecided"), to 3 ("disagree"). In the instrument, we included items with different intensity related to all three components of organizational commitment - affective, continuance and normative.

In the qualitative component of the study we applied semi-structured interview, aimed to gather data about experience and respondent's opinion about achievement of their engagement in HRD activities and about their commitment to organization. For this instrument under the term "HRD activities", we consider different spectrum of previously described HRD activities - related to organization, formal, informal, self-initiated, etc.

The interview protocol included ten open-ended questions. All questions were pilot tested for clarity with the group of graduate students in andragogy. The interviewees were informed that the interview will be anonym, audio-recorded by interviewer, and transcribed verbatim. Participants were labeled by random names. Interview length were 18 to 30 minutes. The interviews were transcribed, and the key themes were identified.

\section{Data Analyses Techniques}

The collected data were subjected (in the first component) to a few common (frequencies, std. deviation, means, etc. with IBM SPSS Statistics 23) and more complex statistical proceedings (canonical correlation analysis with Dell Software STATISTICA 12.5). To supplement them, for the data collected by interviews, qualitative content analysis was used. The primary purpose of qualitative content analysis was to register different explanations of experience and interviewees' opinion about achievement of their engagement in HRD activities and about their commitment to organization. Three explanations were identified.

\section{Analysis and Discussion}

\section{Quantitative Data}

\section{Relations between frequency of participation in HRD activities and organizational commitment of employees}


Results of canonical correlation test for relationship between frequency of participation in HRD activities and organizational commitment of employees (Table 2) showed that two canonical correlations are significant. By using the cutoff correlation of 0.3 to select variables for each variable set, the variables in the set of frequency of participation in HRD activities (FP) correlated with the first canonical variate were: lack of employee engagement activities and HRD activities related to learning of business principles and standards. Taken as a pair, these variates suggest that lack of employee engagement activities followed almost only by HRD activities related to learning of business principles and standards leads to a lack of affective commitment of employees, i.e. to reduction of their attachment to organization.

The second canonical variate included learning about using organizational data basis and absence of HRD activities directed to obtain conflict solving skills. This pair of canonical variates reveal that reduction of HRD activities to learning about using organizational data base combined with absence of HRD activities directed to obtain conflict solving skills lead to lack of normative commitment of employees, i.e. to the loss of loyalty to organization.

\section{Relations between content of HRD activities and organizational commitment of employees}

Canonical correlation test for relations between content of HRD activities and organizational commitment of employees (Table 2) revealed that two canonical correlations are significant. By using the cutoff correlation of 0.3 to select variables for each variable set, the one variable in the set of content of $H R D$ activities related to organizational learning was included -- "single-loop" learning activities. In organizations which operates in a hierarchical way, executive management and employees usually generates specific, subjective, implicit logical, for specific group characteristically information, that are difficult to generalize. In the organizational hierarchy, unlike to other employees, top managers generate an abstract, objective, explicitly logical, comparable information that could be generalized. Differences in perception between first line managers and employees at one hand, and senior executives and top managers, at the other hand are in the core of: tensions, distorted information, and creation of conditions for downsizing performance. Such practice does not encourage the development of creativity, or any kind of conditions necessary for the improvement of organizational performance, which is the main goal to any HRD professional or department. It has potential only for "maintaining the current level of efficiency in the implementation of the acquired knowledge with the possibility for obtaining new but fragmented, functional knowledge and skills of employees through participation in traditional educational and training programs" (Ovesni, 2014: 44). These variates suggest that learning in organization only through "single loop" HRD activities affect loss of loyalty (lack of normative commitment) to organization.

The second canonical variate included "double-loop" learning activities and overall organizational learning. This pair of canonical variates reveal that learning as a rigorous review of processes in which the error originally appeared and in completely restructuration of these processes, together with learning about some organizational determinants (culture, tradition, history, etc.) could raise up affective commitment (attachment to organization) of employees.

\section{Relations between applicability of knowledge and skills obtained through HRD activities and organizational commitment of employees}

Third research question asked about a relationship between applicability of knowledge and skills obtained through HRD activities and organizational commitment of employees. Canonical correlation test (Table 2) revealed that one canonical correlation is significant. The variable which correlated with the first canonical variate was "application of knowledge and skills obtained through HRD activities only in case of error". Taken as a pair, these variates suggest that application of knowledge and skills obtained through HRD activities only in case of error leads to lack of loyalty, i.e. normative commitment. Apparently, if employees obtained some new knowledge and skills during participation in HRD activities, they expect that organization take care about content of these activities, and that organization expect that they apply it to their work-tasks. Nevertheless, if utilization of these knowledge and skills is limited only to cases when previous behavior is not sufficient, or in the case that it leads to error, they could lose confidence to organization that leads to weaker normative commitment.

\section{Relations between motivation for organizational and job-related learning and organizational commitment of employees}

Results of canonical correlation test for relationship between motivation for organizational and job-related learning and organizational commitment of employees (Table 2) showed that one canonical correlation is significant. The variable which correlated with the first canonical variate was "autonomy in learning". Taken as a pair, these variates suggest that 
respondents with more autonomy for organizational and job-related learning are more loyal to their organizations. Autonomy represent the reflection of power (influence) and knowledge in context; it is critical in obtaining the status in own profession, job or among coworkers (Ovesni, 2014). Therefore, it is not surprising that employees with higher level of autonomy in job-related learning express stronger loyalty (normative commitment) to their organizations.

\section{Relations between learning through evaluation of HRD activities and organizational commitment of employees}

Fifth research question asked about a relationship between learning through evaluation of HRD activities and organizational commitment of employees. Canonical correlation test for relations between learning through evaluation of HRD activities and organizational commitment of employees (Table 2) revealed that one canonical correlations is significant. The variable which correlated with the first canonical variate was "discussions about application of learned". This pair of canonical variates reveals that employees who reported that they discuss about possibilities to apply knowledge and skills obtained in HRD activities express stronger continuance commitment (gratitude). One of reasons could be that specific ("how-to") knowledge could support their decision to stay in organization.

\section{Relations between support to employees' learning and organizational commitment of employees}

Canonical correlation test for relations between support to employees' learning and organizational commitment of employees (Table 2) revealed that three canonical correlations are significant. The first canonical variate included support to share knowledge with co-workers and lack of support to employees' learning. This pair of canonical variates reveal that employees who been asked to share their knowledge with co-workers and those who don't have support for learning express lack of normative commitment, loyalty. First pair is especially interesting, because it reveals possibility that employees perceive sharing own knowledge as unethical practice, and potential high value given to job-related knowledge. Obliging someone to give something valuable to someone "for free" could trigger them to reconsider obligation to remain in organization due to ethical reasons. Moreover, absence of support for their job-related learning, especially if they are intertwined with some other factors of job dissatisfaction (lower status, job insecurity, low salary, poor work conditions, etc.) could also lead to lack of normative commitment to organization. The second canonical variate included learning about job, in free time, and full support for formal professional education. This pair of canonical variates reveal that respondents who learn about job in their own time, and those who have full support for formal professional education express higher affective commitment, attachment to organization. The third canonical variate included learning through social networks in free time, non-material support for formal professional education, provision of the on-the-job trainings, and support to participate in seminars, conferences, or other out-door learning activities. Taken as a pair, these variates suggest that respondents with more support for personally important job-related learning given by organization express stronger continuance commitment (gratitude) to organization.

\section{Relations between availability of job-relevant information and organizational commitment of employees}

Results of canonical correlation test for relationship between availability of job-relevant information and organizational commitment of employees (Table 2) showed that two canonical correlations are significant. The first canonical variate included possibility for knowledge sharing via social networks, and for social networking among co-workers during working time. Taken as a pair, these variates suggest that respondents with more freedom in usage of social networks express stronger continuance commitment (gratitude). The second canonical variate included open access to all organizational data and freedom in using the Internet on the job. Taken as a pair, these variates suggest that employees that freely access all data necessary for successful job performance express higher attachment to organization (affective commitment). One of explanation is that employees tend to be creative in job-related problem solving, that they need open access to all jobrelevant information, and through this - express tendency to work in a learning organization that support interconnectivity, creation of system for maintaining and sharing knowledge relevant to organization.

\section{Qualitative Data}

Development of employees in organization is performing through different learning process that involve a broad spectrum of different HRD activities (Knowles, et al., 1998; Marsick, et al., In Chalofsky, et al., 2014; Ovesni, 2014; Swanson and Holton, 2001). Concerning responses given by interviewees in this study, HRD activities encompass: activities organized by employers that could be performed indoors or outdoors, activities organized by employees, or self-initiated activities. Although plentiful HRD activities are recognized by interviewees, availability and offer of them is very limited. Interviewees 
employed in the organizations that have high performance, or those involved into industries characterized by rapid changes, with emphasized need for innovations underline necessity for continuing learning. For example:

Jovana: "Considering that my industry is characterized by rapid changes, where day-to-day learning, that is supported by my company, is necessity. It is very important to be informed about all relevant changes. Once a year we have intensive training about new standards and regulative, and new methods. Also, during working time we can approach to all required information by different organizational web-portals".

As important effects of learning in organization, employees usually itemize: obtaining new knowledge, development of good relationship with co-workers, building up self-confidence, deeper knowledge about own job, and with the context for its performance. Some of responses given by interviewees describes these effects:

Zorica: "I would like to say that HRD activities organized by my organization not only that contribute to obtaining new knowledge, but also to development of good relationship and better communication with co-workers".

Olivera: "Learning and continuing attendance to seminars boost up my self-confidence."

Marko: "Trainings organized by my company helped me to obtain insight into processes and purposes of my organization."

Based on obtained responses, we could conclude that most of them consider that participation of employees in HRD activities contribute to organizational commitment. Only few of them categorically deny it.

How to explain relations between HRD activities and organizational commitment? Reflections of interviewees about that issue are different. However, it is possible to extract a few explanations based on their statements. First explanation is based in opinion that planning and realization of different learning activities express concerns for employees, and expression of security of their jobs:

Nemanja: "Education organized by company contribute to attachment and to loyalty to organization. That way, employees could get impression that company care about them and their skills, and that company have long-term plans with these employees."

Zoran: "Care about promotion and development of employees expressed through organizing learning activities develop empathy to my organization."

The base for second explanation is conviction that development of organization is intertwined with development of employees. Development of competences necessary for optimal performance, building up self-confidence of employees, and drive organization toward optimal performance:

Nemanja: "I consider that what I learned in my company obligate me to be loyal, and drives me to further learning".

Nevena: "Satisfaction with learned helped me to perform my job better, and acknowledgement that I am better than before drives me to stronger commitment to my organization."

Vladimir: "I feel that when I learn what I want, and my company benefits from it, we grow up together."

The main characteristic of third explanation is opinion that organizational commitment is grounded in organizational climate that is developed through learning and understanding of own job, and context for its realization. Furthermore, as additional encouragement for stronger commitment to organization, interviewees emphasize relationship of employees with processes in organization.

Aleksandar: "By learning in the workplace context somehow I accept job characteristics. These knowledge is only mine, and as consequence, they form my commitment to organization."

Tijana: "Workplace learning contribute to better understanding of the work-related processes and relationships in organization, and what you understand, is closer and more intimate, so you feel it as something what belongs to you."

Zlatija: "Learning in organization influence me... because create bonds with organization, helps me to understand organizational values." 
However, besides opinion that participation in HRD activities contribute to development of organizational commitment, some interviewees point to circumstances when such development is missing. For example, when participation of employees in HRD activities is not perceived as possibility to improve quality of own performance, but as a request to obtain a job. In such case interviewees underline that commitment to organization is not matter of choice, but necessity. In some cases, if they want to hold their work-position employees are obligated that in a certain period achieve a prescribed amount of points (by participation at seminars) or to pass some tests.

Gorica: "HRD activities in our organization are usually directed to obtaining more points, and then, it is imposed. We participate in some seminars just because possibility to obtain points, not because possibility to learn something related to our work. To me, participation in such activities can't raise up my organizational commitment ... it means only that l'll get some points for it."

Commitment to organization, besides engagement of employee in HRD activities, is caused by broad spectrum of different factors: organization culture, climate, management, tradition, critical reflection of achievements, feedback, research and development, optimal performance requests, possibility to accomplish organizational mission and vision, possibility to understand organizational philosophy and politics, realization of ethical principles, etc. In our study, interviewees emphasized importance of: manager-employee relation, overall organizational climate, quality of communications between employees, acknowledgement with and acceptance of work processes, salary, work conditions, etc.

Jelena: "Loyalty and commitment to organization are influenced by top managers who are capable to recognize efforts, efficacy, and commitment to job that are performed by workers."

Marija: "I would say that incomes provided by organization are base of loyalty, and that commitment is based on income arguments."

Vladan: "Loyalty comes from job satisfaction, that is primary satisfaction with salary and work conditions".

\section{Conclusion}

This study showed deep and complex interconnections of HRD activities and organizational commitment. Through first, quantitative component we learned that, at the one hand, limited scope and inadequate offer of HRD activities, as well as limitation to "single loop" HRD activities, issues with applying obtained knowledge and skills, forcing employees to share own knowledge with others, leads to the weaker normative commitment of employees, i.e. to reduction of employees' loyalty to organization. Moreover, limited scope and inadequate offer of HRD activities also lead to weaker affective commitment of employees, to reduction of their attachment to organization.

At the other hand, "double-loop" learning activities, learning about organizational culture, learning about job in free time, full support for formal professional education, and free access to all data necessary for successful job performance could raise up affective commitment of employees, i.e. to make attachment to organization stronger. Autonomy in job-related learning could trigger stronger loyalty (normative commitment) to organizations, while active learning through evaluation of HRD activities with more support for personally important job-related learning given by organization, and more freedom in usage of social networks raise up continuance commitment (gratitude).

Explanation of interplay between of HRD activities and organizational commitment given through second qualitative component of our study revealed that quality of these relationship depends on understanding the role of learning and participation in HRD activities - as reflection of organizational carefulness and long-term plans of human resource management, as prerequisite for improvement of organizational performance, as path of understanding and acknowledging with job character, as means to acceptance of organizational context, or as requirement for holding obtained work-position.

These findings could have consequences on human resource management practice. They pointed out necessity for differentiated approach to HRD activities design. As Ryan wrote: "When the circumstances warrant special attention, significant benefit is gained when a manager secures a personal commitment from the employee to be accountable for the desired results. Commitment is the key" (Ryan, 2003: 521, In Ovesni, 2014).

Although this study is among a very few studies for this topic, the usage of explanatory sequential design to explore the interconnection of human resource development activities and organizational commitment may require further researches 
with different samples, in different social context, or with longitudinal design and are necessary for better generalizability of results.

\section{Literature}

[1] Antonacopoulou, E. P. (2001). The Paradoxical Nature of The Relationship Between Training and Learning. Journal of Management Studies, 38(3), 327-350

[2] Bartlett, K. R. (2001). The Relationship Between Training and Organizational Commitment: A Study in the Health Care Field. Human Resource Development Quarterly, 12(4), 335-352

[3] Bennett, E. E., and Bierema, L. L. (2010). The Ecology of Virtual Human Resource Development. Advances in Developing Human Resources, 12(6), 632-647

[4] Chalofsky, N. E., Rocco, T. S., Morris, M. L. (Eds.) (2014). Handbook of Human Resource Development. Hoboken, NJ: John Wiley \& Sons, Inc.

[5] Creswell, J. W.\& Plano Clark, V. L. (2011). Designing and Conducting Mixed Methods Research. Los Angeles (etc.): SAGE Publications, Inc.

[6] Garavan, T. N., McGuire, D., O'Donnell, D. (2004). Exploring Human Resource Development: A Levels of Analysis Approach. Human Resource Development Review, 3(4), 417-441

[7] Greene, C. J., Caracelli, J. V. \& Graham, W. F. (1989). Toward a Conceptual Framework for Mixed-Method Evaluation Designs. Educational Evaluation and Policy Analysis, 11 (3), 255-274.

[8] Hamlin, B., \& Stewart, J. (2011). What is HRD? A definitional review and synthesis of the HRD domain. Journal of European Industrial Training, 35 (3), 199-220

[9] Hartung, K. J., and Wilson, D. G. (2016). Conversational Moves That Matter: Bridging Learning Outcomes and Patterns of Speech in Informal Cross-Organizational Conversations Among Top-Level Leaders. Adult Education Quarterly, 66(3), 254-272

[10] Joo, B. (2010). Organizational Commitment for Knowledge Workers: The Roles of Perceived Organizational Learning Culture, Leader-Member Exchange Quality, and Turnover Intention. Human Resource Development Quarterly, 21(1), 69-85

[11] Klein, H. J., Becker, T. E., Meyer, J. P. (2012). Commitment in Organizations: Accumulated Wisdom and New Directions. New York, NY: Routledge.

[12] Knowles, M., Holton, E. F. III, Swanson, R. A. (1998). The adult learner: The definitive classic in adult education and human resource development, 5th edition. Houston, TX: Gulf Publishing Company.

[13] Mathieu, J. E. (1991). A Cross-Level Nonrecursive Model of the Antecedents of Organizational Commitment and Satisfaction. Journal of Applied Psychology, 76(5), 607-618

[14] Matović, N. (2013). Kombinovanje kvantitativnog i kvalitativnog pristupa u pedagoškom istraživanju [Combining Quantitative and Qualitative Approaches in Pedagogical Research]. Beograd, SR: Institut za pedagogiju i andragogiju, Filozofski fakultet Univerziteta u Beogradu.

[15] Meyer, J. P. (2014). Employee Commitment, Motivation, and Engagement: Exploring the Links, In M. Gagne (Ed.): The Oxford Handbook of Work Engagement, Motivation, and Self-Determination Theory. New York, NY: Oxford University Press, 33-49.

[16] Miroshnik, V. (2013). Organizational Culture and Commitment: Transmission in Multinationals. Houndmills, UK: Palgrave Macmillan.

[17] Onwuegbuzie, A. \& Collins, K. (2007). A Typology of Mixed Methods Sampling Designs in Social Science Research. The Qualitative Report, 12 (2), 281-316. 
[18] Ovesni, K. (2014). Organizacija koja uči: andragoška perspektiva [Learning Organization: Andragogical Perspective]. Beograd, SR: Institut za pedagogiju i andragogiju, Filozofski fakultet Univerziteta u Beogradu.

[19] Reio, T. G., Jr. (2013). Exploring the links between adult education and human resource development: Learning, risk-taking, and democratic discourse. New Horizons in Adult Education \& Human Resource Development, 25(4), 4-11

[20] Reis, H. T., Sprecher, S. (Eds.) (2009). Encyclopedia of human relationships, Volume 1. Thousand Oaks, CA: SAGE Publications, Inc.

[21] Rigg, C., Stewart, J., Trehan, K. (Eds.) (2007). Critical Human Resource Development: Beyond Orthodoxy. Harlow, GB: Pearson Education Ltd.

[22] Rowden, R. W. (2002). The Relationship Between Workplace Learning and Job Satisfaction in U.S. Small to Midsize Businesses. Human Resource Development Quarterly, 13(4), 407-425

[23] Ruona, W. E. A. (2000). Core Beliefs in Human Resource Development. A Journey for the Profession and Its Professionals. Advances in Developing Human Resources, 2(3), 1-27

[24] Sambrook, S. (2002). Factors Influencing Learning in Work: a comparison of two research projects (European- and United Kingdom-based). European Educational Research Journal, 1(3), 522-537

[25] Slattery, J. P., Selvarajan, T. T., Anderson, J. E. (2006). Influences of New Employee Development Practices on Temporary Employee Work-Related Attitudes. Human Resource Development Quarterly, 17(3), 279-303

[26] Swanson, R. A., and Holton III, E. F. (2001). Foundations of Human Resource Development. San Francisco, CA: Berret-Koehler Publishers, Inc.

[27] Thurston Jr., P. W., D'Abate, C. P., Eddy, E. R. (2012). Mentoring as an HRD Approach: Effects on Employee Attitudes and Contributions Independent of Core Self-Evaluation. Human Resource Development Quarterly, 23(2), 139-165

[28] Tkaczyk, B. (2017). A balanced approach to professional HRD consulting: Lessons from the field. Global Business and Organizational Excellence, 36(4),6-16

[29] Watkins, K. E., \& Marsick, V. J. (1993). Sculpting the learning organization: Lessons in the art and science of systemic change. San Francisco, CA: Jossey-Bass.

[30] Wilton, N. (2013). An introduction to Human Resource Management, $2^{\text {nd }}$ edition. Los Angeles, CA, London, GB: Sage.

Table 1. Internal reliability coefficients for CA, AKS, ML, LE, SL, and AI scales

\begin{tabular}{|l|l|l|}
\hline Instrument & Number of items & Cronbach's a coefficient \\
\hline Frequency of participation in organized HRD activities (FP scale) & 18 & 0.83 \\
\hline Content of HRD activities (related to organizational learning) (CA scale) & 10 & 0.69 \\
\hline $\begin{array}{l}\text { Applicability of knowledge and skills obtained through HRD activities to } \\
\text { practice (AKS scale) }\end{array}$ & 16 & 0.80 \\
\hline Motivation for organizational and job-related learning (ML scale) & 6 & 0.69 \\
\hline Learning through evaluation (LE scale) & 7 & 0.64 \\
\hline Support to employees' learning (SL scale) & 17 & 0.71 \\
\hline Availability of job-relevant information (Al scale) & 5 & 0.66 \\
\hline Organizational commitment (OC scale) & 41 & 0.94 \\
\hline
\end{tabular}

Table 2. Canonical correlation test for relationship between HRD activities and commitment of employees 


\begin{tabular}{|c|c|c|c|c|c|c|}
\hline \multirow{6}{*}{ FREQUENCY OF PARTICIPATION } & \multicolumn{4}{|c|}{ Chi-Square Tests with Successive Roots Removed } & \multirow{2}{*}{ p } & \multirow{2}{*}{$\lambda^{\prime}$} \\
\hline & Cncl R & $\mathrm{Cncl} \mathrm{R}{ }^{2}$ & $x^{2}$ & $\mathrm{df}$ & & \\
\hline & 0.365 & 0.134 & 195.375 & 108 & 0.000 & 0.720 \\
\hline & 0.256 & 0.065 & 110.0023 & 85 & 0.036 & 0.831 \\
\hline & \multicolumn{3}{|c|}{ 1st Cncl Var. } & \multicolumn{3}{|c|}{ 2nd Cncl Var. } \\
\hline & \multicolumn{3}{|c|}{ lack of affective commitment } & \multicolumn{3}{|c|}{ lack of normative commitment } \\
\hline employee engagement activities & \multicolumn{3}{|c|}{-0.589} & \multicolumn{3}{|c|}{1} \\
\hline business principles and standards & \multicolumn{3}{|l|}{0.406} & \multicolumn{3}{|l|}{0.706} \\
\hline using organizational data basis & \multicolumn{3}{|l|}{1} & \multicolumn{3}{|l|}{0.473} \\
\hline \multirow[t]{3}{*}{ Conflict solving skills } & \multicolumn{3}{|l|}{1} & \multicolumn{3}{|l|}{-0.414} \\
\hline & & Percent of & riance & $36.46 \%$ & & \\
\hline & & Redundan & & $12.53 \%$ & $16.61 \%$ & \\
\hline & Chi-So & Tests with & cessive Rc & Removed & & \\
\hline & Cncl R & $\mathrm{Cncl} \mathrm{R}{ }^{2}$ & $x^{2}$ & $\mathrm{df}$ & $p$ & $\Lambda$ \\
\hline CONTENT OF HRD ACTIVITIES (related to & 0.395 & 0.156 & 360.376 & 220 & 0.000 & 0.544 \\
\hline organizational learning) & 0.358 & 0.128 & 260.184 & 189 & 0.000 & 0.644 \\
\hline & $1 \mathrm{st} \mathrm{Cn}$ & & & 2nd Cncl Var & & \\
\hline & lack of & ative comm & & affective com & & \\
\hline "single-loop" learning activities & 0.397 & & & 1 & & \\
\hline "double-loop" learning activities & 1 & & & 0.672 & & \\
\hline lack of organizational learning & 1 & & & -0.506 & & \\
\hline & & Percent of & riance & $54.46 \%$ & & \\
\hline & & Redundan & & $17.19 \%$ & $14.07 \%$ & \\
\hline & Chi-So & Tests with & cessive Rc & Removed & & \\
\hline & $\begin{array}{l}\text { Cncl } \\
\mathrm{R}\end{array}$ & $R^{2}$ & & $d f$ & p & $\lambda^{\prime}$ \\
\hline APPLICABILITY OF KNOWLEDGE AND & $\begin{array}{l}0.43 \\
6 \\
\end{array}$ & 90 & 308 & 144 & 0.000 & $\begin{array}{l}0.6 \\
18 \\
\end{array}$ \\
\hline $\begin{array}{l}\text { SKILLS (obtained through HRD activities to } \\
\text { practice) }\end{array}$ & $1 \mathrm{st} \mathrm{Cn}$ & & & Percent of va & & $\begin{array}{l}36 . \\
46 \\
\%\end{array}$ \\
\hline & lack of & ative comm & & Redundancy & $12.53 \%$ & $\begin{array}{l}16 . \\
61 \\
\%\end{array}$ \\
\hline only in case of error & 0.556 & & & 1 & & \\
\hline & Chi-So & Tests with & cessive Rc & Removed & & \\
\hline & Cncl R & Cncl R2 & $x^{2}$ & df & p & $\Lambda$ \\
\hline & 0.409 & 0.167 & 168.466 & 64 & 0.000 & $\begin{array}{l}0.7 \\
55\end{array}$ \\
\hline $\begin{array}{l}\text { MOTIVATION FOR ORGANIZATIONAL AND } \\
\text { JOB-RELATED LEARNING HRD ACTIVITIES }\end{array}$ & 1st Cn & & & Percent of va & & $\begin{array}{l}89 . \\
42 \\
\%\end{array}$ \\
\hline & normat & mmitment & & Redundancy & $15.15 \%$ & $\begin{array}{l}15 . \\
64 \\
\%\end{array}$ \\
\hline autonomy in learning & 0.635 & & & 1 & & \\
\hline & Chi-So & Tests with & cessive Rc & Removed & & $\lambda^{\prime}$ \\
\hline & Cncl R & Cncl R2 & $x 2$ & $\mathrm{df}$ & $p$ & $\Lambda$ \\
\hline IFARNING THROUGH FVAU UATION & 0.436 & 0.190 & 166.059 & 49 & 0.000 & $\begin{array}{l}0.75 \\
8\end{array}$ \\
\hline LEARIVIVG ITRUUGT EVALUATIUIV & 1st Cn & & & Percent of va & & $\begin{array}{l}55.3 \\
7 \% \\
\end{array}$ \\
\hline & continu & commitme & & Redundancy & $16.16 \%$ & $\begin{array}{l}18.1 \\
7 \% \\
\end{array}$ \\
\hline discussions about application of learned & 0.462 & & & 1 & & \\
\hline
\end{tabular}


Table 2 (continued). Canonical correlation test for relationship between HRD activities and commitment of employees

\begin{tabular}{|c|c|c|c|c|c|c|}
\hline \multirow{7}{*}{ SUPPORT TO EMPLOYEES' LEARNING } & \multicolumn{4}{|c|}{ Chi-Square Tests with Successive Roots Removed } & \multirow{2}{*}{$p$} & \multirow{2}{*}{$\lambda^{\prime}$} \\
\hline & Cncl R & Cncl R2 & $x^{2}$ & $\mathrm{df}$ & & \\
\hline & 0.457 & 0.209 & 318.366 & 136 & 0.000 & $\begin{array}{l}0.58 \\
6\end{array}$ \\
\hline & 0.297 & 0.088 & 179.147 & 112 & 0.000 & $\begin{array}{l}0.74 \\
0\end{array}$ \\
\hline & 0.282 & 0.079 & 124.245 & 90 & 0.010 & $\begin{array}{l}0.81 \\
2\end{array}$ \\
\hline & \multicolumn{3}{|c|}{ 1st Cncl Var. } & \multicolumn{3}{|l|}{ 2nd Cncl Var. } \\
\hline & \multicolumn{3}{|c|}{ lack of normative commitment } & \multicolumn{3}{|c|}{ affective commitment } \\
\hline support to share knowledge with co-workers & \multicolumn{3}{|c|}{0.424} & \multicolumn{3}{|c|}{1} \\
\hline lack of support & \multicolumn{3}{|l|}{0.381} & \multicolumn{3}{|l|}{1} \\
\hline learning about job, in free time & \multicolumn{3}{|l|}{1} & \multicolumn{3}{|l|}{0.626} \\
\hline full support for formal professional education & \multicolumn{3}{|l|}{1} & \multicolumn{3}{|l|}{0.378} \\
\hline & \multicolumn{3}{|c|}{ 3rd Cncl Var. } & $\begin{array}{l}\text { Percent of } \\
\text { variance }\end{array}$ & & $\begin{array}{l}51.3 \\
5 \%\end{array}$ \\
\hline & \multicolumn{3}{|c|}{ continuance commitment } & Redundancy & $20.05 \%$ & $\begin{array}{l}16.6 \\
8 \%\end{array}$ \\
\hline learning through social networks in free time & \multicolumn{3}{|c|}{0.669} & & & \\
\hline non-material support for frm. prof. education & \multicolumn{3}{|l|}{0.504} & & & \\
\hline provision of the on-the-job trainings & \multicolumn{3}{|l|}{0.381} & & & \\
\hline support for seminars, conferences, etc. & \multicolumn{3}{|c|}{0.328} & & & \\
\hline \multirow{6}{*}{$\begin{array}{l}\text { AVAILABILITY OF JOB-RELEVANT } \\
\text { INFORMATION }\end{array}$} & \multicolumn{4}{|c|}{ Chi-Square Tests with Successive Roots Removed } & & \\
\hline & Cncl R & Cncl R2 & \begin{tabular}{l|l}
2 \\
\end{tabular} & $\mathrm{df}$ & $p$ & $\Lambda^{\prime}$ \\
\hline & 0.412 & 0.170 & 216.414 & 85 & 0.000 & 0.696 \\
\hline & 0.308 & 0.095 & 105.379 & 64 & 0.001 & 0.838 \\
\hline & $1 \mathrm{st} \mathrm{Cnc}$ & & & 2nd Cncl Var. & & \\
\hline & continu & commitme & & affective comn & ent & \\
\hline knowledge sharing (social networks) & 0.494 & & & 1 & & \\
\hline allows social networking among co-workers & 0.331 & & & 1 & & \\
\hline open access to all organizational data & 1 & & & 0.617 & & \\
\hline allows using the Internet on the job & 1 & & & 0.957 & & \\
\hline & & Percent & variance & $48.72 \%$ & & \\
\hline & & Redund & & $18.92 \%$ & $15.75 \%$ & \\
\hline
\end{tabular}

